
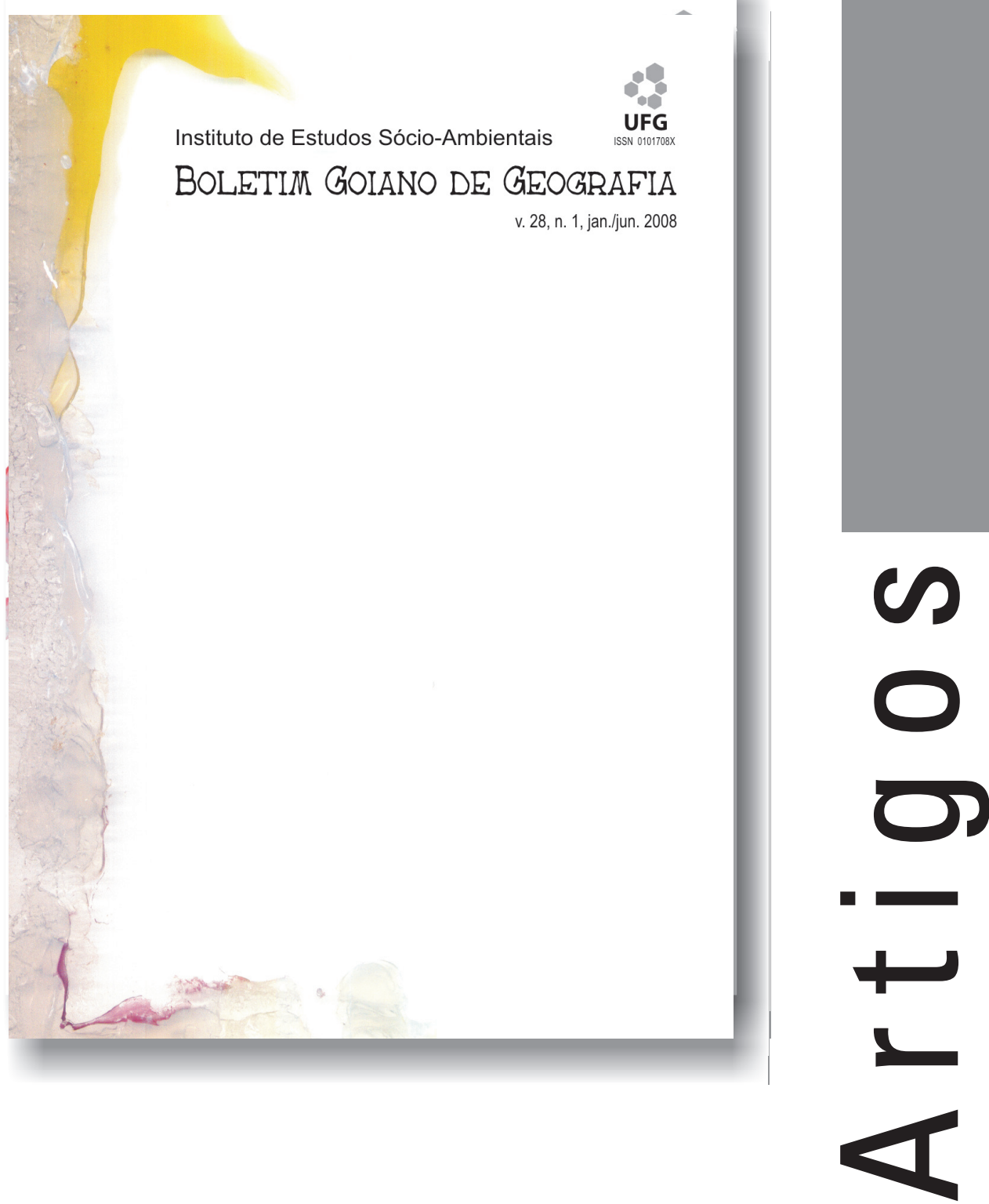


\title{
Contribuição ao entendimento do fenômeno das enchentes do Rio Vermelho na cidade de Goiás, GO
}

\author{
Contveitrition to the agreement of the phenomenon of floods of the red river in the city of Goiás, GO
}

\author{
Marcelo Antunes Cavalcanti - IESA/UFG \\ marceloantunesufg@yahoo.com.br \\ Luciana Maria Lopes - IESA/UFG \\ luciana@iesa.ufg.br \\ Marlon Nemayer Celestino de Pontes - IESA/UFG \\ mnemayer@yahoo.com.br
}

\section{Resumo}

A histórica cidade de Goiás - G0, localizada a cerca de $149 \mathrm{~km}$ da capital do estado, Goiânia, foi fundada durante a "corrida do ouro", no século XVIII, às margens de um rio aurífero. Desde então vem sofrendo problemas decorrentes das cheias do rio Vermelho, que corta a cidade. Os objetivos do trabalho são os de contribuir para a compreensão da gênese das enchentes, e apontar medidas de controle. Para tal, vários procedimentos foram realizados incluindo-se: análise dos condicionantes geoambientais da bacia (clima, geologia, geomorfologia, solos e uso/ ocupação da terra); busca de informações sobre a implantação do núcleo urbano; resgate do histórico de ocorrência das cheias, e indicação de medidas preventivas. Concluiu-se que as enchentes resultam de um quadro fisico propício caracterizado pela presença de serras, vales encaixados, canyons, pavimentos rochosos, vertentes íngremes, solos rasos, desmatamento, e clima marcado por chuvas altamente concentradas no verão. Somam-se a esses aspectos a ocupação da bacia hidrográfica realizada de modo desordenado, sem nenhum planejamento prévio, e a localização do sítio urbano, edificado em local totalmente impróprio. Sugere-se que as medidas preventivas devem ser de duas ordens abrangendo o reordenamento de uso da bacia e obras de infra-estrutura.

Palavras-chave: Rio Vermelho, Cidade de Goiás, condicionantes geoambientais, localização imprópria, enchentes

\begin{abstract}
Located $149 \mathrm{~km}$ away from the state capital of Goiania, the historic city of Goias, G0, was created during the $18^{\text {th }}$ Century "gold rush" to the Vermelho River, which cuts through the city. Ever since, flooding problems have plagued the area. The objectives of this work are to contribute to the understanding and genesis of the flooding spells, and indicate potential control measures. With these objectives in mind, several approaches were utilized, including: an analysis of the geo-environmental aspects of the watershed (climate, geology, geomorphology, soils, and land/use occupation); a research of how the urban area was developed; a historical research of flooding occurrences; and indication of preventative measures. It has been concluded that the flooding occurrences result from combined factors characterized by the presence of mountains, enclosed valleys, canyons, steep and rocky slopes, shallow soils, deforestation, and a summer weather pattern known for concentrated heavy rains (or flash floods). Beyond these factors, the use and occupation of the watershed was done haphazardly with no previous planning, and the urban area was built in a totally inappropriate location. Preventative measures are restricted to a two-fold approach of re-ordering the watershed's land use and building infrastructure projects.
\end{abstract}

Key-words: Vermelho river, City of goias, geoenvironmental factors, inappropriate location, floods

\begin{tabular}{|l|c|c|c|c|c|c|}
\hline Boletim Goiano de Geografia & Goiânia - Goiás - Brasil & v. 28 & n. 1 & p. 167-186 & jan. / jun. & 2008 \\
\hline
\end{tabular}




\section{Introdução}

A cidade de Goiás, antiga capital do estado homônimo, reconhecida pela Unesco como Patrimônio Mundial da Humanidade, tem sua origem na obcecada corrida pelo ouro da primeira metade do século XVIII. Fundada em 1727 pelo bandeirante Bartolomeu Bueno da Silva Filho, inicialmente com o nome de Arraial de Sant'Anna (Palacin, 1979), foi arquitetada às margens de um rio aurífero (rio Vermelho), espraiando-se por significativa parte de sua planície de inundação, em um momento histórico onde o planejamento foi atropelado pela sede de enriquecimento fácil e rápido. Seu sítio urbano vem sofrendo, desde a origem, graves problemas relacionados ao fenômeno das enchentes que periodicamente assolam a cidade.

As cheias são documentadas desde o século XVIII e acarretam grandes destruições, principalmente ao centro histórico, edificado em estilo Barroco e tombado pelo IPHAN. A cidade é cortada ao meio pelo rio, sendo interligada por três pontes que já foram levadas várias vezes pela força das águas. A última grande enchente do Vermelho ocorreu na manhã do dia 31/12/2001, após uma precipitação pluviométrica de 140,9 mm antecedida por vários dias chuvosos. Cerca de 85 edificações da área tombada pela Unesco sofreram sérios danos, e aproximadamente 35 foram totalmente destruídas ( $\mathrm{O}$ Popular, 04/01/2002). O IPHAN, juntamente com a Defesa Civil e a Prefeitura Municipal de Goiás, calculou o prejuízo em R\$ 8.650.000.00. Contudo, as perdas de ordem simbólica, artística e cultural são imensuráveis e, praticamente, irreversíveis.

\section{Localização da área de estudo}

A área de pesquisa trata-se da porção da bacia do rio Vermelho à montante da cidade de Goiás (alta bacia), situada entre as coordenadas $50^{\circ} 00^{\prime}$ $50^{\circ} 08^{\prime}$ de longitude oeste, e $15^{\circ} 50^{\prime}-16^{\circ} 00^{\prime}$ de latitude sul. Tal bacia situa-se inteiramente dentro do município de Goiás (Figura 1), no quadrante SD-22Z-C-V. Possui área aproximada de $111,6 \mathrm{~km}^{2}$, suas nascentes mais distantes estando cerca de $17 \mathrm{~km}$ da cidade. A histórica cidade de Goiás-GO situa-se nas bordas da antiga região do Mato Grosso Goiano, na porção noroeste do estado, a 149km da capital, Goiânia, estando a ela ligada por rodovia estadual pavimentada (GO - 070). 


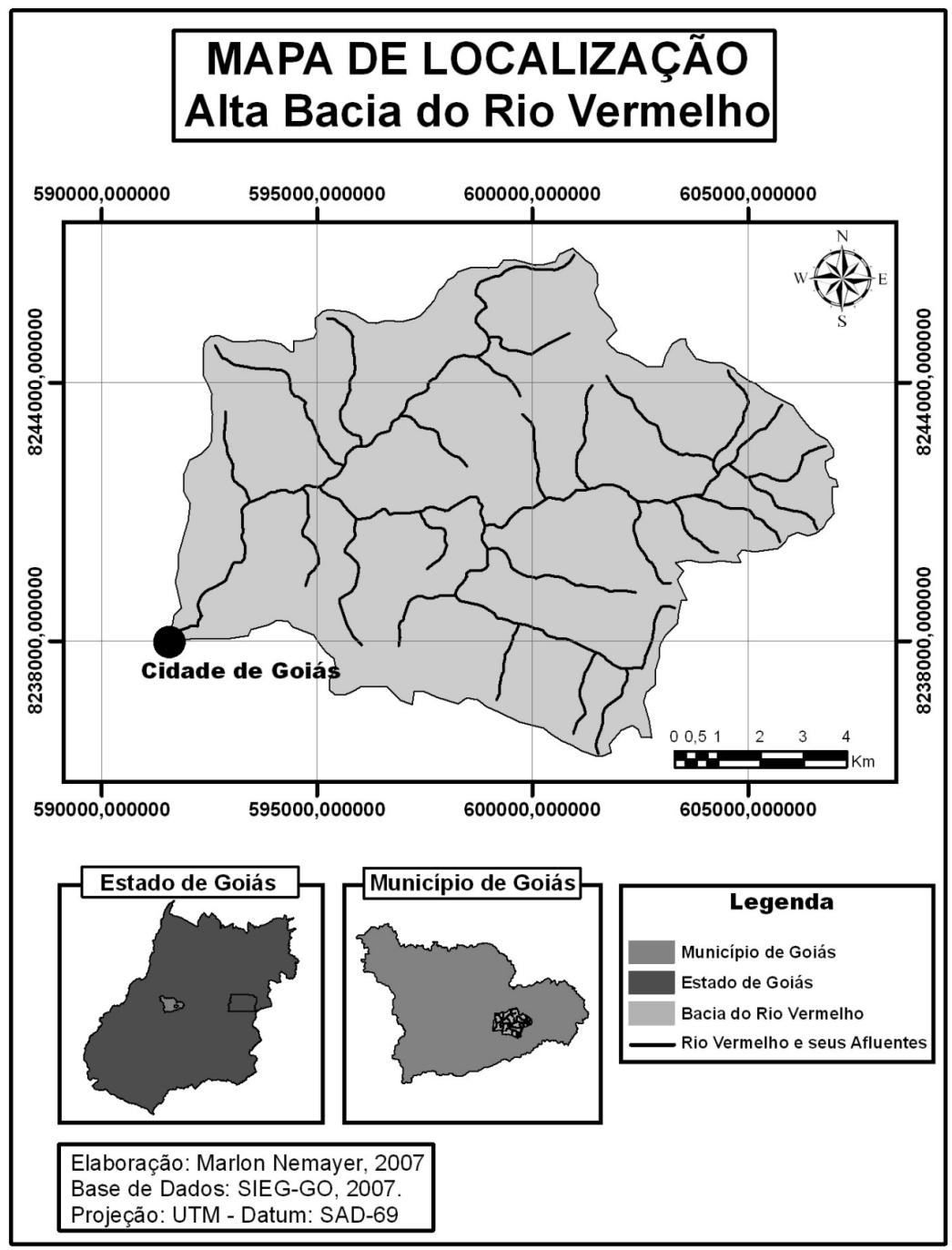

Figura 1- Mapa de localização da bacia do Rio Vermelho à montante da cidade de Goiás - GO.

\section{Condicionantes geoambientais da área}

A geologia da bacia do rio Vermelho é marcada pela presença de litologias muito variadas que datam do Arqueano/Proterozóico, e que foram 
submetidas a vários ciclos tectônicos e metamórficos. Do ponto de vista da representatividade areolar destacam-se o Grupo Goiás Velho (Agv; Greenstone belt de Goiás, ou cinturão de rochas verdes, em cinza escuro no mapa da Figura 2), o Complexo Granitóide-Gnáissico (Agrgn, em cinza claro), e o Grupo Serra Dourada (Msd; em cinza médio) (CPRM, 1999; modificado).

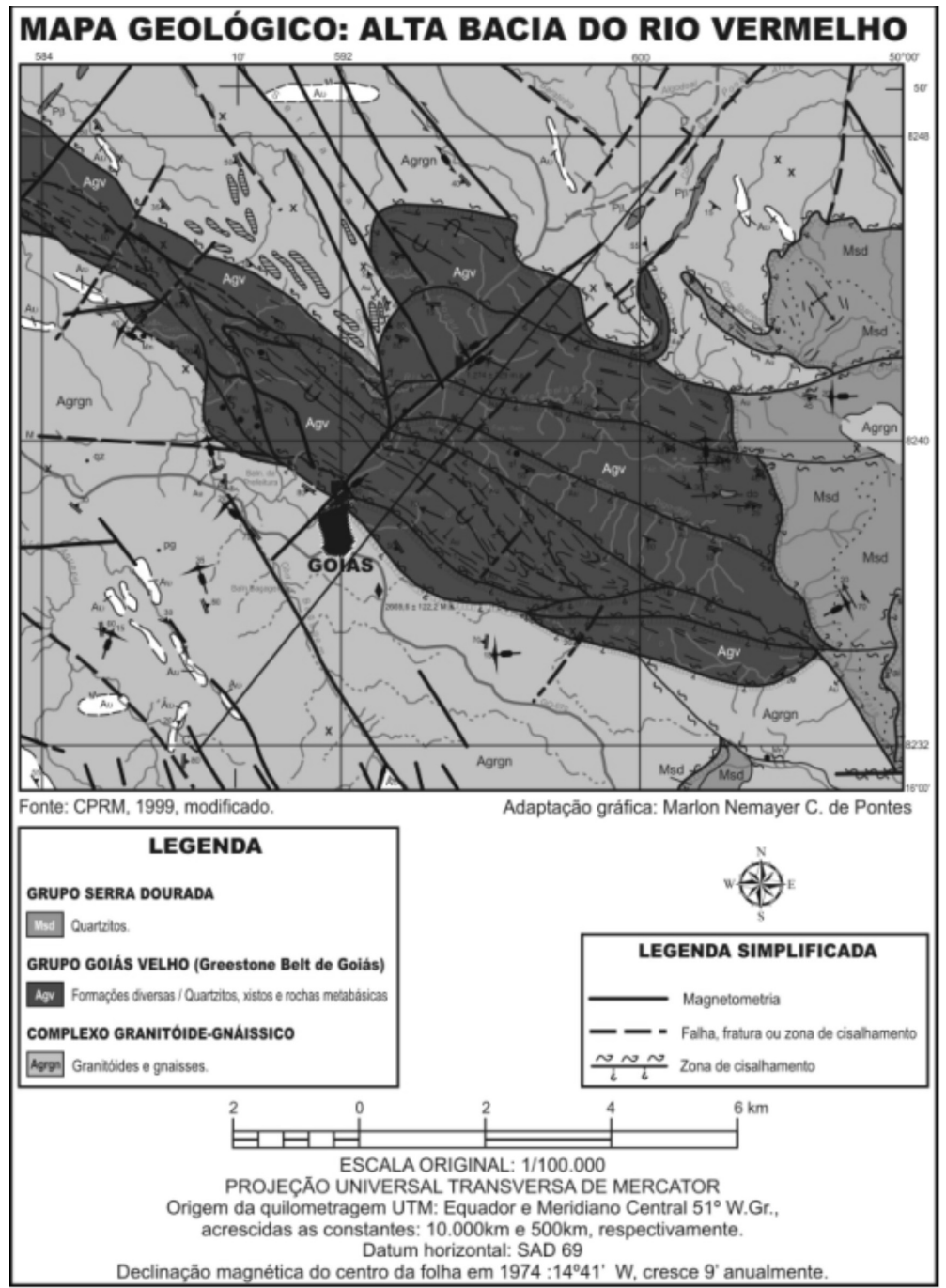

Figura 2 - Mapa geológico da alta bacia do Rio Vermelho e adjacências. 
Esses três grandes conjuntos rochosos, ou domínios morfoestruturais, destacam-se por sua natureza e estilo tectônico. As variadas litologias do Grupo Goiás Velho (Agv, em cinza escuro no mapa da Figura 2), representadas por quartzitos, micaxistos, e rochas vulcânicas metabásicas/metaultrabásicas, aparecem notavelmente alinhadas segundo a direção geral NWSE. Destacam-se do, comparativamente, homogêneo Complexo GranitóideGnáissico (Agrgn, em cinza claro na Figura 2), constituído por granitóides gnaissificados e/ou gnaisses, e que regionalmente representa o embasamento cristalino sobre o qual edificou-se o Grupo Goiás Velho. Nos quartzitos da Serra Dourada (Msd) encontram-se parte das nascentes do rio Vermelho.

Notar que a Cidade de Goiás encontra-se quase que totalmente edificada sobre o Complexo Granitóide-Gnáissico, no contato com o Grupo Goiás Velho.

Quanto ao relevo, a área de pesquisa insere-se nas unidades Planalto do Alto Tocantins-Paranaíba e Depressão do Araguaia.

O Planalto do Alto Tocantins-Paranaíba elaborado, em sua maioria, sobre as rochas do Grupo Goiás Velho, é uma subunidade do Planalto Central Goiano e se caracteriza, no geral, por relevos serranos de formas aguçadas com vertentes íngremes e/ou convexas. As altitudes, muito variáveis, chegam a superar os 1000 metros. A unidade geomorfológica denominada Depressão do Araguaia (Mamede et al., 1983) elaborada, na região, sobre as rochas do Complexo Granitóide-Gnáissico caracteriza-se, diferentemente do Planalto do Alto Tocantins-Paranaíba, pelo relevo arrasado e altitudes significativamente menores, entre 400 e $500 \mathrm{~m}$.

As diferenças altimétricas (Figura 3) das duas unidades geomorfológicas acima citadas guardam uma relação ímpar com a resistência litológica dos compartimentos geológicos que as sustentam. Os quartzitos do Grupo Goiás Velho (Greenstone Belt) e do Grupo Serra Dourada apresentam maior resistência ao intemperismo comparativamente às rochas do Complexo Granitóide-Gnáissico tendo sido, por isto, menos erodidos, sustentando serras e a maior parte da linha de cumeada da alta bacia do Vermelho. Em contrapartida, as áreas de domínio do Complexo Granitóide-Gnáissico sofreram intenso processo de meteorização, principalmente de natureza química, respondendo pelo rebaixamento máximo da bacia, à cota dos 400 metros. 


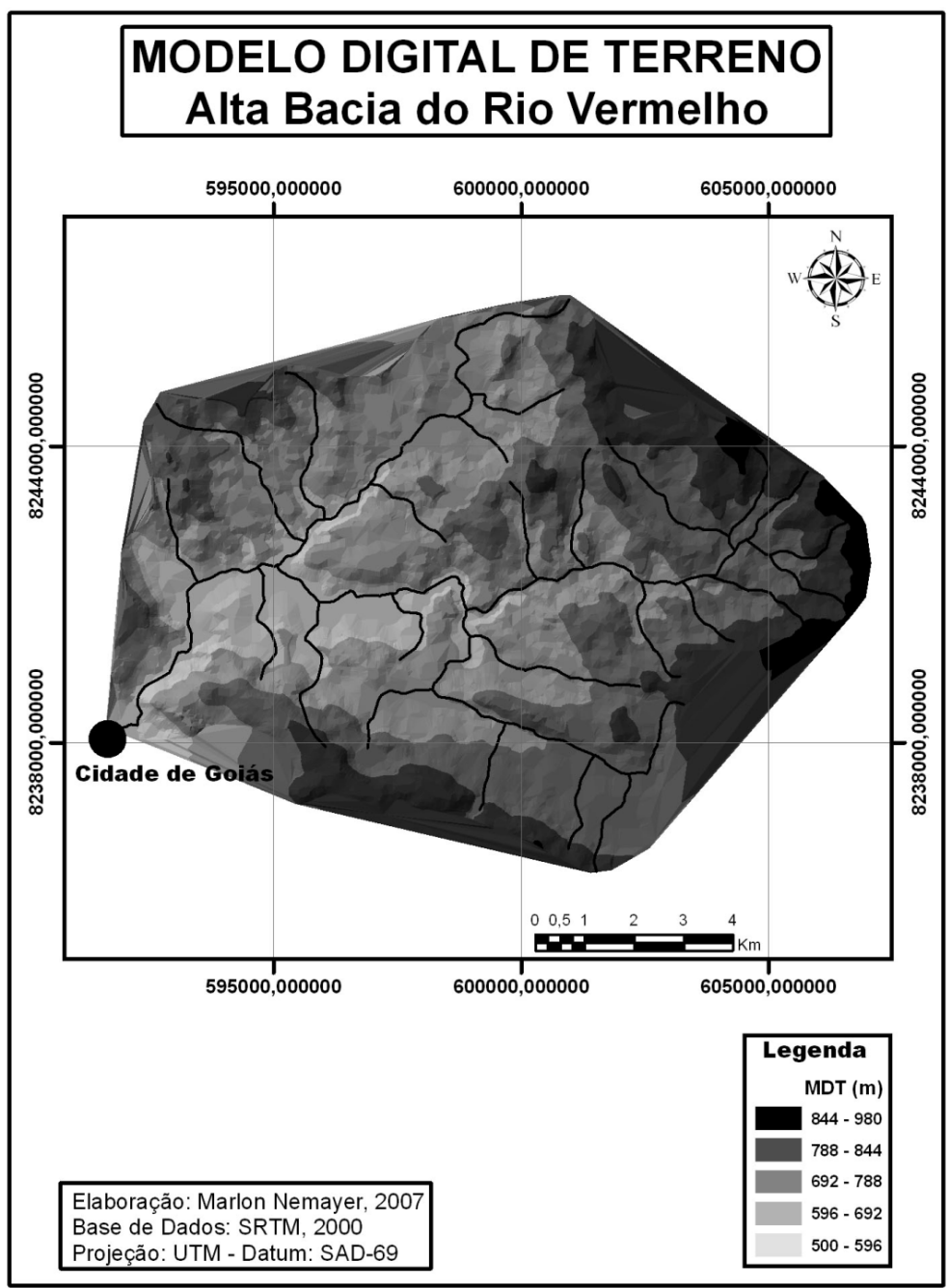

Figura 3 - Altitudes na porção da bacia do Rio Vermelho à montante da Cidade de Goiás

A rede de drenagem mostra-se, quase que em sua totalidade, controlada por direções estruturais, a exemplo do que ocorre com o córrego DigoDigo, drenagem controlada por zona de cisalhamento que marca o contato mecânico entre a formação homônima e a formação Limeira. As bruscas mudanças do seu curso, em ângulos de $90^{\circ}$, o paralelismo de seus afluentes, e os 
altos ângulos de confluência destes com o Digo-Digo são evidências do fato. Além do córrego Paciência, o leito do rio Vermelho é também condicionado por falhamento que controla seu curso na direção E-W e que, próximo à cidade de Goiás, verte para a direção NE-SW.

Um fator de grande importância que merece ser abordado diz respeito à forma da bacia. O "índice de Circularidade", citado por Christofoletti (1988), é um parâmetro importante porque indica o tempo necessário para que ocorra a concentração d'água dos pontos mais distantes em um mesmo lugar. De modo geral, quanto mais a morfologia geral da bacia tender ao arredondamento, maior será a chance de ocorrerem enchentes. Para tanto, calcula-se a relação entre a área da bacia e a área do círculo de mesmo perímetro, o que implica num índice de circularidade de aproximadamente 0,85 considerado muito elevado, já que o valor máximo é 1, para bacias totalmente circulares. Esse dado aponta para o fato de a alta bacia do rio Vermelho ser mais sujeita à ocorrência de enchentes.

Em termos areolares, três classes de solos destacam-se na bacia: Cambissolos, Argissolos e Latossolos Vermelho-Amarelos. A alta declividade presente na maior parte do terreno justifica a predominância de solos rasos e pouco desenvolvidos.

A bacia do rio Vermelho configura-se como uma das primeiras áreas do território goiano a serem ocupadas pelos colonizadores. Este processo pode ser desdobrado em duas fases. A primeira forma de interferência está ligada à exploração do ouro de aluvião que teve início na calha do rio Vermelho, e dos seus principais afluentes, no segundo quarteto do século XVIII. Contudo, pouco mais de 50 anos foram suficientes para que tivesse início um período de linear decadência da produção aurífera (Palacin, 1979) sendo estimulado, a partir de então, o desmatamento da bacia para produção de gêneros alimentícios e de pastagens para a criação do gado vacum. Entretanto, a mudança na forma de uso não foi imediata: paulatinamente as terras foram sendo ocupadas pela agropecuária ${ }^{1}$, à medida que as principais lavras de ouro de aluvião esgotavam-se e consolidavam-se as políticas governamentais para ruralização da sociedade, com objetivo de aumentar a arrecadação e encontrar uma saída à fragilidade econômica da região.

O tratamento da imagem de satélite CBERS-2, datada de 10 de junho de 2006, permitiu a compreensão do uso da área atualmente. Os resultados foram agrupados em três classes (Figura 4): cobertura vegetal natural, que reúne formações savânicas (cerrado) e florestais, afloramentos de rocha e zonas antropizadas, esta última englobando pastagens, sede de fazendas, plantações, etc. 


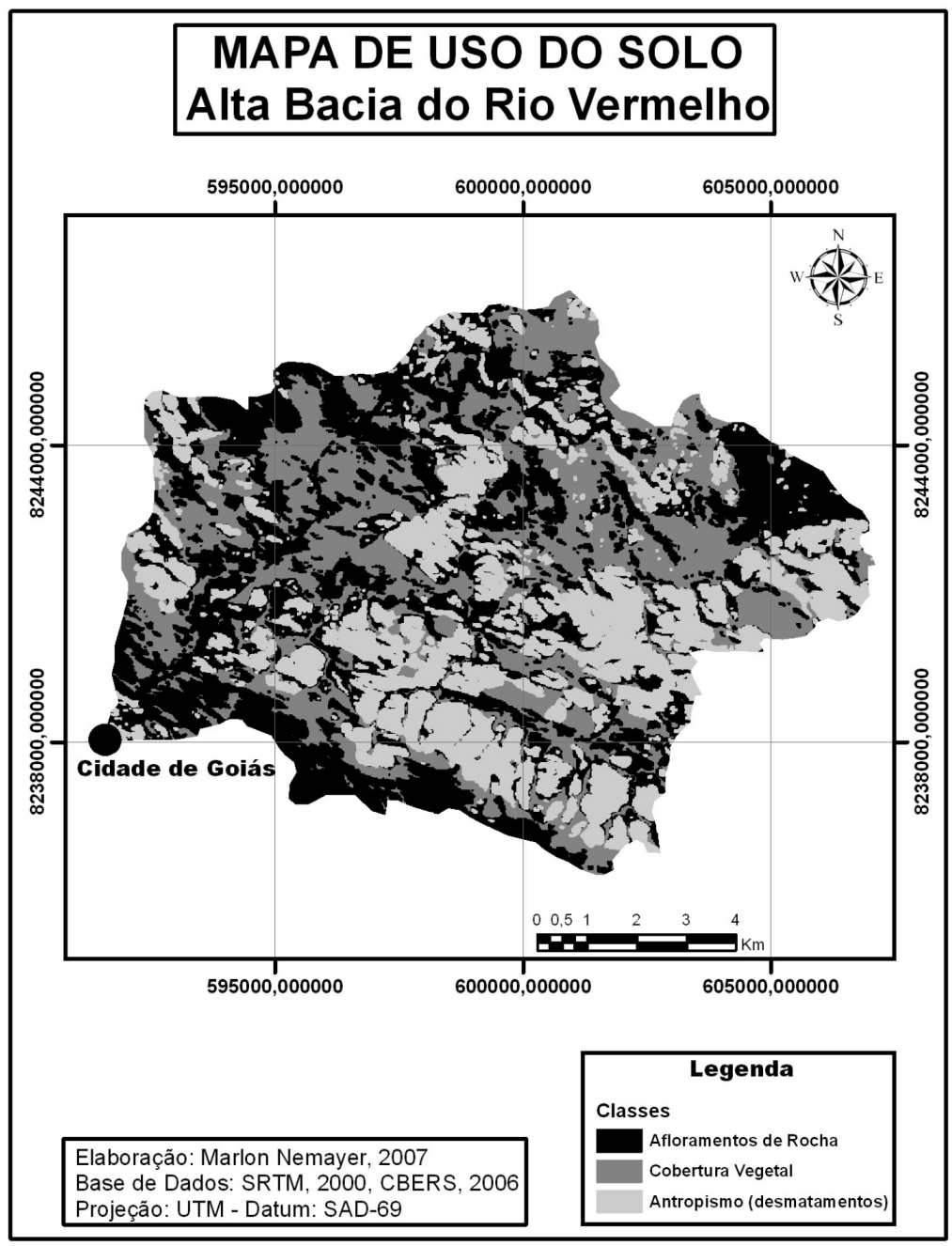

Figura 4 - Uso da terra na alta bacia do Rio Vermelho.

O tratamento das informações demonstrou que $25 \%$ da área é antropizada, 38\% ainda é coberta por vegetação natural, e 37\% representa afloramentos rochosos. Uma observação superficial induz afirmar que a cobertura vegetal encontra-se relativamente bem preservada. Levantamento realizado pela Agência Ambiental do Estado de Goiás revelou, entretanto, que aproximadamente $80 \%$ das matas ciliares do trajeto do rio Vermelho, à montante 
da Cidade de Goiás, já foram retiradas (Correio Brasiliense, 2002). A análise dos condicionantes geoambientais da bacia, e os fortes empecilhos à ocupação remetem à constatação de que praticamente todas as terras que apresentam o mínimo de possibilidade de ocupação já o foram.

Vários estudos comprovam que ambientes desmatados apresentam maiores taxas de perda de solos, com entulhamento dos vales e diminuição progressiva das taxas de infiltração d'água (Bertoni e Lombardi Neto, 1985; Casseti, 1991). O aumento do componente geomorfológico perpendicular favorece o escoamento superficial concentrado e altera drasticamente o ritmo fluvial. Esses fatores concursam à ampliação da variação das vazões do rio, já elevadas na região devido à alta concentração de chuvas em um curto período do ano, tendendo a favorecer a ocorrência de cheias durante o período chuvoso.

\section{Aspectos climáticos}

O clima da área de estudo pode ser classificado como Tropical Subúmido (Aw), com duas estações bem definidas: uma quente e úmida, e outra predominantemente seca, com grande amplitude térmica diária durante o inverno.

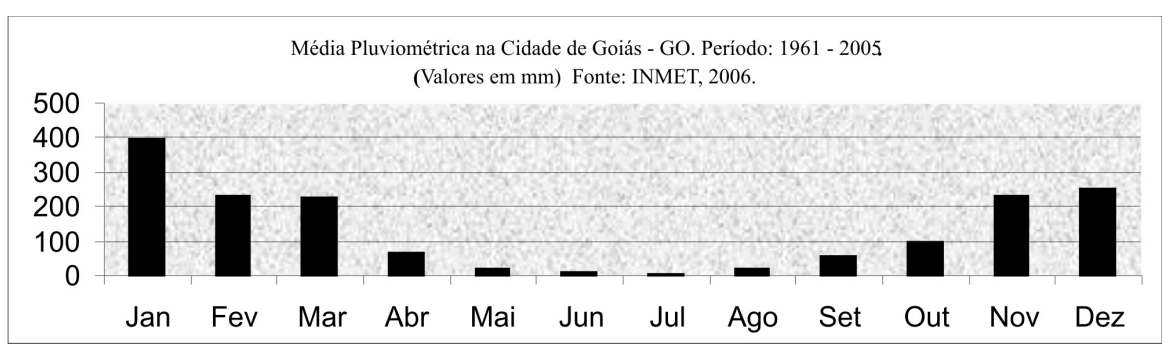

Figura 5 - Média pluviométrica da Cidade de Goiás - GO.

Quanto à análise da relação entre precipitações acumuladas e cheias do Vermelho, três ${ }^{2}$ picos de vazão (inundações) são comparados com a quantidade das chuvas ocorridas nos seis dias que antecederam as enchentes de 1980, 1981 e 2001 (Tabela 1), totalizando uma semana. 
Quadro 1 - Dados pluviométricos e enchentes do rio Vermelho na Cidade de Goiás - GO

\begin{tabular}{|c|c|c|c|}
\hline \multirow{2}{*}{ Relação dos Dados Pluviométricos com as Cheias do Vermelho (INMET, 2006) } \\
\hline \multirow{3}{*}{ Data das cheias } & \multicolumn{3}{|c|}{ Quantidade de Chuvas (mm) } \\
\cline { 2 - 4 } & Últimos 6 Dias & Dia da Cheia & Total \\
\hline $19 / 02 / 1980$ & 256,6 & 121,8 & 378,4 \\
\hline $29 / 03 / 1981$ & 179,8 & 150,6 & 330,4 \\
\hline $31 / 12 / 2001$ & 124,1 & 140,9 & 265 \\
\hline
\end{tabular}

Conclui-se que parece ser crucial a ocorrência de altos índices pluviométricos capazes de saturar os solos e provocar a intensificação do escoamento superficial nos dias que antecedem o episódio da cheia. A simples observação dos dados permite constatar que as enchentes ocorrem após fortes precipitações de verão que superam os $100 \mathrm{~mm}$ em menos de $24 \mathrm{~h}$. Entretanto, verifica-se que nem sempre o grande aumento no volume d'água do rio ocorre em anos muito chuvosos. As precipitações muitas vezes são extremamente concentradas, de forma que algumas enchentes foram registradas em anos considerados secos, abaixo da média pluviométrica.

Quando ocorrem excepcionalidades climáticas, as águas vertem das serranias rochosas e das áreas mais declivosas de solos rasos e saturados para a calha dos afluentes e para o próprio rio Vermelho que, após atravessar a Serra do Cantagalo através de estreito canyon, deságua seu grande volume de água nas planícies do Vermelho, já dentro da cidade de Goiás, causando as enchentes.

\section{Breve histórico das enchentes}

Constata-se que as enchentes ocorrem desde a edificação da urbe e, aparentemente, não possuem um caráter de ciclicidade temporal (Tabela 2). Com as descrições e relatos pode-se constatar que, geralmente, durante as cheias, mesmo nas maiores, o rio nunca passa mais de $4 \mathrm{~h}$ fora de sua calha. As inundações, portanto, são breves, mas deixam um terrível rastro de destruição. 
Quadro 2 - Enchentes do rio Vermelho documentadas na Cidade de Goiás.

\begin{tabular}{|c|c|c|}
\hline Enchentes & Intensidade & Danos \\
\hline 1- 09/01/1782 & Média & Levou as três pontes. \\
\hline 2- 19/02/1839 & Alta & Destruiu a Igreja da Lapa, pontes, causou mortes \\
\hline 3- 1864 & Média & Danificação de pontes e prédios. \\
\hline 4- Jan/1958 & Baixa & $?$ \\
\hline 5- 19/02/1980 & Baixa & Alagamentos e destruição de murada de quintais \\
\hline 6- 29/03/1981 & Média & Danificação de pontes e destruição de prédios. \\
\hline 7- 17/12/1989 & Baixa & Alagamentos e danificação de prédios. \\
\hline 8- 31/12/2001 & Alta & Destruição de pontes e edificações. \\
\hline 9- 13/02/2007 & Baixa & Alagamentos \\
\hline
\end{tabular}

Nos documentos pesquisados, foi possível perceber a existência de duas vertentes diferenciadas que explicam as enchentes da cidade de Goiás: naturalista e antrópica. A primeira afirma que se trata de um fenômeno natural e que, com ou sem intervenção humana, as inundações ocorreriam. Essa tese é alicerçada em relatos históricos. Em contraposição, emerge a vertente antrópica defendendo que o homem é o grande culpado pelas catástrofes ambientais que vêm ocorrendo na cidade de Goiás. Essa idéia se apóia nos índices de desmatamento e retirada da mata ciliar do rio e, ainda, na constatação de que o tempo de retorno das cheias está sempre diminuindo.

No século XVIII (1782), época na qual a alta bacia se encontrava praticamente íntegra, ocorreu uma cheia. Mas a maior de todas as inundações do Vermelho se deu em 1839, época do início da ruralização da antiga sociedade aurífera, ocasião em que o uso das terras era ainda restrito. Sobre o rio Vermelho, o naturalista Johann Emanuel Pohl, ao percorrer a capitania de Goiás no primeiro decênio do século XIX, afirmou: "na estação seca esse rio é muito insignificante, mas na época das chuvas enche-se consideravelmente.” Pohl (1976, p 140).

Todas as enchentes documentadas com precisão quanto ao mês ocorreram durante a quadra chuvosa: dezembro, janeiro, fevereiro e março. Sobre as características do clima neste período do ano Johann Emanuel Pohl escreve: 
Durante a minha estada de dois anos nesta capital, tive bastante oportunidade de observar o clima. A estação chuvosa começa em meados de setembro; os dias de chuva aumentam em número, violência e duração dos aguaceiros até fevereiro ou março. Aliás, nestes meses era quando se mostrava mais intensa a fúria do tempo. Várias tempestades se armavam simultaneamente, na maioria vindas de leste, e descarregavam-se habitualmente de manhã e de tarde, com uma impetuosidade de trovões e raios, de que na Europa apenas se pode fazer uma idéia. (POHL, 1976, p. 124).

\section{A enchente de 2001}

Poucos dias após a última grande cheia (31/12/2001), os jornais iniciaram uma maratona de acusações desencontradas sobre os culpados pelo incidente. No dia 02 de janeiro de 2002 o jornal "O Popular" veiculou a seguinte matéria: "Desleixo Ambiental Provocou Inundação”. Várias causas foram, por diferentes atores, aventadas para explicar a catástrofe citandose, entre elas, a destruição das matas ciliares das margens do rio Vermelho e da vegetação permanente das encostas, o assoreamento do rio e de seus afluentes, provocado pelo garimpo e desmatamento. O Correio Brasiliense de 06/01/2002 também mencionou as possíveis causas do ocorrido na matéria intitulada "Rio Vermelho Pede Socorro".

Pressionados pela cobrança da população em descobrir e punir os culpados por uma das maiores "catástrofes ambientais" do Estado de Goiás, representantes do Ministério Público - MP, da Agência Goiana de Meio Ambiente e Recursos Naturais - Agência Ambiental, e da Secretaria de Segurança Pública e Justiça montaram uma comissão e se empenharam em fazer investigações. Na ocasião foi apontado que, além da degradação ambiental, lagoas construídas irregularmente, de maneira precária, e sem um estudo de impacto ambiental, nas margens do rio Vermelho e de seus afluentes poderiam, com as enxurradas, terem transbordado, levando grande volume d'água para os ribeirões e rios já inundados pelo temporal. (O Popular, 15/01/2002).

A comissão não deixou claro as causas da cheia, porém solicitou à Superintendência de Geologia e Mineração um estudo sobre o episódio que resultou na publicação do relatório: "O Rio, a Cidade de Goiás e os Limites Ambientais" . Nesta, que é a investigação mais aprofundada realizada até então pelo poder público, concluiu-se que "a catástrofe ocorrida na cidade de Goiás, em 31 de dezembro de 2001, foi um acidente hidrológico natural”. 
(AGIM, 2002, p. 21) e que, com ou sem desmatamento, a enchente teria afetado a cidade (O Popular, 29/03/2002).

\section{A cidade e o drama das enchentes: compreendendo o problema}

A maior parte da exploração do ouro de aluvião concentrou-se inicialmente às margens do rio Vermelho, e logo se multiplicaram os arraiais. $\mathrm{O}$ arraial de Sant' Ana (atual cidade de Goiás) foi fundado em 1727, pelo bandeirante Bartolomeu Bueno da Silva Filho, próximo aos principais núcleos de mineração descobertos até então.

Um dos primeiros terrenos a cederem espaço à edificação da cidade foi a planície de inundação do rio Vermelho. Na atualidade, a maioria das construções situadas às margens desse rio são tombadas pelo Instituto do Patrimônio Histórico e Artístico Nacional - IPHAN.

As características do meio físico apontam para o fato de que a cidade de Goiás, antigo arraial de Sant‘Anna, foi construída num local totalmente impróprio. Vários fatores concorrem à tal afirmação. Primeiramente, a cidade foi edificada justamente onde o rio Vermelho, vindo de áreas serranas mais altas e declivosas, com alta rugosidade topográfica, e com até $1000 \mathrm{~m}$ de altitude, pertencentes ao Planalto do Alto Tocantins-Paranaíba, espraia-se nas suas planícies elaboradas nos terrenos arrasados onde se inicia a cidade de Goiás.

Destaca-se o alto índice de circularidade da bacia $(0,85)$, à montante da cidade de Goiás, índice que aponta para a tendência à ocorrência de enchentes.

Quanto aos solos, nas vertentes de altas declividades inseridas no domínio das serranias elaboradas nas rochas mais resistentes do Grupo Goiás Velho, os processos morfogenéticos predominam relativamente aos pedogenéticos resultando na existência de solos mais rasos dos tipos Cambissolos e Argissolos, sendo comuns as exposições rochosas que constituem superfícies impermeáveis. Tais solos, por sua pouca profundidade e estrutura, são facilmente saturáveis o que faz com que, na época das chuvas de verão, o excedente de água não infiltrado passe também a contribuir para o aumento da vazão do rio Vermelho.

Fato relevante que deve ser notado, e que também favorece as enchentes, é que a Serra do Cantagalo, ou Serra de São Francisco, constitui-se num paredão rochoso no sopé do qual se encontra a cidade de Goiás. Ime- 
diatamente antes do rio Vermelho entrar na cidade, ao atravessar a Serra do Cantagalo é estreitado numa garganta controlada por falhamento e esculpida, no tempo geológico, pelo ação das águas do rio. Vindas de montante, as águas do Vermelho, confinadas no canyon profundo e estreito, aumentam de velocidade para compensar o estreitamento do canal, e assim velozes e turbulentas alcançam as planícies do Vermelho, na cidade de Goiás. São graves as conseqüências da ocupação de tais setores aplainados do relevo, marginais aos rios, sugestivamente denominados de "planícies de inundação" desde que sujeitos a tal fenômeno quando das cheias. Suas áreas, salvo locais de alto gradiente, são geralmente aplainadas devido ao acúmulo de sedimentos.

Em suma, são vários os condicionantes que, juntos, formam um cenário propício à ocorrência de enchentes, destacando-se : características geológicas; - existência de rochas mais resistentes que sustentam as serranias do Grupo Goiás Velho, entre elas citando-se a Serra do Cantagalo, litoestruturas que respondem pelas maiores altitudes da região; - ocorrência de pavimentos rochosos, impermeáveis, expostos nas áreas serranas; - existência de canyon pela qual o Vermelho é premido a passar, na Serra do Cantagalo, antes da sua entrada na cidade de Goiás, e - edificação de parte da cidade nas planícies do Vermelho. Quanto à geomorfologia, destaca-se o relevo acidentado à montante da cidade, com serras e morrarias de vertentes íngremes. Nas áreas mais declivosas os solos comuns são os Cambissolos, seguidos pelos Argissolos. São, no geral, rasos e distróficos, apresentando baixa capacidade de saturação. Quando, ao cenário composto pelos fatores geológicos, geomorfológicos, pedológicos, e de uso da terra, somam-se eventos de chuvas excepcionais, altamente concentradas , configura-se quadro propício à ocorrência de enchentes.

\section{Sinalizando propostas}

O centro histórico Vilaboense, construído em estilo Barroco, e com muitos dos elementos característicos da organização urbana medieval e vernacular portuguesa (Coelho, 1997), tem mais de 70\% de suas construções dos séculos XVIII e XIX bem preservadas (O Popular, 14/12/01), é considerada a primeira ocupação pelos colonizadores europeus em território goiano.

O Patrimônio Cultural de um povo é sua maior riqueza, e uma das mais importantes heranças a serem deixadas às futuras gerações. Os casa- 
rões, as ruas, becos e avenidas das cidades históricas, além de representarem uma série de significados sentimentais na vida de muitos, conservam uma estreita relação com o que se pode chamar de "materialização da cultura", e da organização social, política e econômica de uma dada sociedade em um determinado tempo pretérito. Assim como afirma o historiador espanhol Luiz Palacin, que estudou o século do ouro em Goiás: "A urgência do momento não admitia dilações. Há ouro, há água, isto basta” (Palacin, 1979, p. 25). Isso reforça a idéia de que a construção do sítio urbano vilaboense se deu em um local totalmente impróprio. Contudo, o que nos resta agora é articular estratégias de ação no sentido de minimizar os riscos aos quais está submetido este valioso patrimônio.

Para minimizar os riscos de novas enchentes na cidade de Goiás, deve ser criado, em caráter de urgência, o comitê da bacia do Alto Rio Vermelho que funcionará como instrumento norteador de ações de planejamento e gestão da bacia junto ao poder público, e à sociedade civil.

O comitê de gestão da bacia hidrográfica, entretanto, deve receber toda a assistência do poder público, desde o envio de técnicos e especialistas para mapeamento e elaboração do plano de manejo da bacia até a execução de possíveis obras estruturais de contenção de cheias. Um problema tão complexo como esse, que envolve um grande número de variáveis, deve ser enfrentado com um programa de alta magnitude, com várias ações a curto, médio e longo prazo. Para tanto, indica-se:

$\checkmark \quad$ Elaboração de um plano de manejo para a bacia, que leve em consideração aspectos ambientais e sócio-econômicos;

$\checkmark \quad$ Programa de recomposição das matas ciliares;

$\checkmark \quad$ Estudos de viabilidade técnica para construção de obras estruturais de contenção de enchentes (barragens, desvios do curso do rio, dutos, etc.);

$\checkmark \quad$ Assistência técnica aos proprietários rurais;

$\checkmark \quad$ Instalação de uma rede de pluviógrafos ao longo da bacia ${ }^{3}$;

$\checkmark \quad$ Ampliação do total de estações de coleta de dados da vazão do rio, e da freqüência das medições ${ }^{4}$;

$\checkmark \quad$ Compatibilizar as ações do Plano Diretor da cidade de Goiás no núcleo urbano com os objetivos do zoneamento da bacia ${ }^{5}$;

$\checkmark \quad$ Amplo programa de educação ambiental.

Na verdade, já existe uma série de órgãos e instituições governamentais criadas com o intuito de implementar as ações necessárias ao cumpri- 
mento de tais objetivos. O grande desafio é conseguir articular parcerias para colocar em prática um planejamento territorial integrado.

\section{Considerações finais}

Ao longo desse estudo, pôde-se perceber que o tratamento do poder público para com a questão das enchentes do rio Vermelho é algo sintomático do que ocorre com outros problemas enfrentados pela sociedade brasileira. Geralmente as ações governamentais são executadas no sentido de resolver temporariamente os problemas através de medidas paliativas, além do que a população não se mobiliza. Tais constatações se evidenciam nas ações adotadas durante as inúmeras vezes que parte da cidade de Goiás foi destruída. As iniciativas sempre objetivaram reerguer as residências, casas comerciais, prédios públicos, ou seja, reconstruir tudo para que o rio reivindique, mais uma vez, suas planícies de inundação, durante um novo episódio de pico pluviométrico.

Mesmo com a última grande enchente de 2001, aparentemente ainda não foi aprendida a lição. Tudo continua como sempre e a cidade de Goiás, à sombra da serra do Cantagalo, a cada estação chuvosa teme a ocorrência de outra enchente. Em fevereiro de 2007 a Defesa Civil da cidade esteve em alerta desde que o rio Vermelho, na ocasião, subiu 3,8 metros além do nível normal, aproximando-se perigosamente do nível da ponte vizinha à casa da poetisa Cora Coralina e quase, portanto, novamente extravasando do seu leito (O Popular, 14/02/2007).

É urgente e necessário o entendimento das reais causas das enchentes, e transformação desse conhecimento em ação. O plano de manejo e de gestão da alta bacia hidrográfica do rio Vermelho, à montante da cidade de Goiás, e obras estruturais, apresentam-se como alternativas eficazes no sentido de, pelo menos, minimizar o problema histórico das enchentes que a assolam.

\section{Notas}

1 Em 1819, ao percorrer a província de Goiás, o naturalista Auguste Saint-Hilaire foi informado pelo governador Fernando Delgado que a economia não poderia mais ser basicamente sustentada pelas minas e que estava despendendo esforços no sentido de desenvolver a agricultura e a pecuária. (Saint-Hilaire, 1975).

2 O INMET possui dados pluviométricos a partir de 1961. Nesse intervalo de tempo conse- 
guimos documentar a ocorrência de quatro enchentes. Contudo, os dados do volume de chuva do mês de dezembro de 1989 apresentam falhas, fato que inviabilizou a análise desta cheia.

3 O único pluviógrafo que se tem conhecimento na bacia do Vermelho pertence à estação de coleta de dados do INMET, localizada na área urbana do município de Goiás. É necessário que se tenha uma rede de pluviômetros espalhada por toda a bacia. Como a coleta de dados do quantitativo de chuvas é um processo relativamente simples, podem ser feitos acordos com proprietários rurais para instalação e controle das medições.

4 Existe atualmente apenas uma unidade de coleta de dados da vazão do rio vermelho: Estação Cachoeira Grande, localizada $5 \mathrm{~km}$ à jusante no núcleo urbano vilaboense. Indica-se a instalação de fluviógrafos ao longo dos córregos Paciência e Digo-Digo, para que se tenha noção dos índices de vazão destes afluentes em momentos de cheia. Além disso, a medição do Vermelho atualmente só é realizada duas vezes no dia ao passo que, quando ocorrem enchentes, o tempo máximo de extravasamento da calha dificilmente excede $4 \mathrm{~h}$.

5 O Plano Diretor da Cidade de Goiás não contempla ações específicas voltadas ao ordenamento territorial do município como um todo, apenas do núcleo urbano. Neste documento, consta a proibição quanto às novas edificações na planície de inundação do Vermelho. Entretanto, bem antes de se pensar em plano diretor a planície do rio já estava ocupada.

\section{Referências}

AGIM, O Rio, A Cidade de Goiás e os Limites Ambientais: Identificando Causas e Indicando Medidas Preventivas. Goiânia, 2002.

BERTONI, J. \& LOMBARDI NETO, F. Conservação do solo. piracicaba: livroceres, 1985.

CASSETI, Valter. Ambiente e Apropriação do Relevo. Goiânia. Editora Contexto, 1991.

CHRISTOFOLETTI, A. Geomorfologia Fluvial. São Paulo, Edgard Blücher/Edusp, 1988.

COELHO, Gustavo Neiva. A formação do espaço urbano nas Vilas do Ouro: o caso de Vila Boa. Dissertação (Mestrado) - Faculdade de Ciências Humanas e Filosofia, Universidade Federal de Goiás, Goiânia, 1997.

CPRM. Programa Levantamentos Geológicos Básicos do Brasil. Sanclerlândia, Folha SE.22-XA-II, Morro Agudo de Goiás, Folha SD.22-Z-C-II, Goiás, Folha SD.22-Z-C-V, Escala 1:100.000. Estado de Goiás. Brasília: editora da CPRM, 1999.

Jornal Correio Brasiliense. Brasília, 06 jan. 2002.

Jornal O Popular. Goiânia, 14 dez. 2001.

. Goiânia, 02 jan. 2002.

. Goiânia, 04 jan. 2002.

. Goiânia, 06 jan. 2002.

. Goiânia, 15 jan. 2002.

. Goiânia, 14 fev. 2002. 
. Goiânia, 29 mar. 2002.

MAMEDE, L. et al. Geomorfologia. In: Projeto RADAMBRASIL-Folha SE.22- Goiânia. Rio de Janeiro, MME/SG. 768 p. (Levantamento de Recursos Naturais, v. 31). 1983

PALACIN, Luiz. O Século do ouro em Goiás. 3º ed. Goiânia: Oriente, 1979.

. Goiás 1722 - 1822: Estrutura e conjuntura numa capitania de minas. Departamento Estadual de Cultura, Goiânia: 1972.

POHL, Johann Emanuel. Viagem no interior do Brasil. São Paulo, USP, 1976.

RESENDE, Paulo et al. Pedologia: bases para distinção de ambientes. Viçosa, Neput, 1995.

SAINT-HILAIRE, Auguste. Viagem a província de Goiás. São Paulo: USP, 1975.

Marcelo Antunes Cavalcante - Professor de geografia da SME e mestando pelo IESA

Luciana Maria Lopes - professora adjunta do IESA/UFG

Marlon Nemayer Celestino de Pontes - mestrando do IESA/UFG

Recebido para publicação em abril de 2008

Aceito para publicação em maio de 2008 